\title{
Diagnosis and Management of a Cryptoglandular Actinomycotic Fistula-in-Ano: An Update on 7 New Cases and a Review of the Literature
}

\author{
Axel Egal ${ }^{1}$, Isabelle Etienney ${ }^{1}$, Heym Beate ${ }^{2}$, Jean Francois Fléjou ${ }^{3}$, Charles André Cuenod ${ }^{4}$, Patrick Atienza ${ }^{1}$, \\ Pierre Bauer ${ }^{1}$ \\ Departments of ${ }^{1}$ Proctological Surgery and ${ }^{2}$ Microbiology, Diaconesses-Croix Saint-Simon Hospital, Paris; ${ }^{3}$ Department of Anatomic Pathology, \\ Saint-Antoine Hospital, APHP, Paris; ${ }^{4}$ Department of Radiology, George Pompidou European Hospital, APHP, Paris, France
}

Purpose: Primary anal actinomycosis of cryptoglandular origin, a rare cause of anal suppurative disease, requires specific management to be cured. The aims of this retrospective study were to describe clinical, morphological, and microbiological features of this entity and to evaluate management practices for new cases observed since 2001.

Methods: This was a retrospective case series conducted at the Diaconesses-Croix Saint-Simon Hospital in Paris.

Results: From January 2001 to July 2016, 7 patients, 6 males and 1 female (median, 49 years), presenting with an actinomycotic abscess with a cryptoglandular anal fistula were included for study. The main symptom was an acute painful ischioanal abscess. One patient exhibited macroscopic small yellow granules ("sulfur granules"), another "watery pus" and a third subcutaneous gluteal septic metastasis. All patients were overweight (body mass index $\geq 25 \mathrm{~kg} / \mathrm{m}^{2}$ ). Histological study of surgically excised tissue established the diagnosis. All the patients were managed with a combination of classical surgical treatment and prolonged antibiotic therapy. No recurrence was observed during follow-up, the median follow-up being 3 years.

Conclusion: Actinomycosis should be suspected particularly when sulfur granules are present in the pus, patients have undergone multiple surgeries or suppuration has an unusual aspect. Careful histological examination and appropriate cultures of pus are needed to achieve complete eradication of this rare, but easily curable, disease.

Keywords: Actinomycosis; Anal abscess; Fistula-in-ano; Cryptoglandular origin

\section{INTRODUCTION}

Actinomycosis is caused by a filamentous slow-growing grampositive bacillus of the Actinomyces genus belonging with other bacteria such as mycobacteria or nocardia of the Actinomycetales

Received: May 2,2017 - Accepted: July 23, 2017

Correspondence to: Axel Egal, M.D.

Department of Proctology, Groupe Hospitalier Diaconesses Croix Saint-

Simon, 125 rue d'Avron, 75020 Paris, France

Tel: +33-6-86-10-22-89, Fax: +33-1-44-64-33-17

E-mail: axelegal1@hotmail.com

ORCID code: https://orcid.org/0000-0002-7265-5781

(C) 2018 The Korean Society of Coloproctology

This is an open-access article distributed under the terms of the Creative Commons Attribution NonCommercial License (http://creativecommons.org/licenses/by-nc/4.0) which permits unrestricted non-

commercial use, distribution, and reproduction in any medium, provided the original work is properly cited. order. Actinomycosis can potentially develop in any location in the human body. Primary anal actinomycosis of cryptoglandular origin, mainly due to Actinomyces israelii, a specific and rare cause of anal suppurative disease, needs to be recognized because it can be cured by combining classical surgical management with an antibiotic regimen that eradicates the infection and prevents recurrence $[1,2]$.

We report here-after an earlier series of 6 cases from January 1983 to December 2000 [1] -7 new cases of cryptoglandular fistula-in-ano due to Actinomyces species and observed in a single proctology unit, bringing to 13 the number of cases described in our unit over 30 years and to 21 the number of cases reported in the literature $[1,2]$. The aim of this retrospective study was to evaluate the clinical and microbiological features, diagnostic criteria and therapeutic management of this rare bacterial infection. 


\section{METHODS}

Case notes and follow-up data on the patients diagnosed from January 2001 to July 2016 were reviewed by 3 clinicians. Informed consent has been received from all patients. Clinical features, diagnostic aspects, and treatment details were analyzed and then compared with data from the previous study of Bauer et al. [1] published in 2006. Cases were included if the cryptoglandular origin of actinomycotic suppuration was confirmed by surgical data. Actinomycosis was proven on the basis of the presence of spherical clusters of filamentous hematoxylin organisms in the excised tissue stained with hematoxylin and eosin and stained positively with Gram's stain and Grocott's methenamine-silver nitrate stain, or with anaerobic cultures for Actinomyces species.

\section{RESULTS}

Since 2001, among more than 5,000 patients operated on for an anal fistula, 7 presented with an actinomycotic abscess (1 patient in 2007, 2009, 2010, 2011, and 2016 and 2 patients in 2012) with an anal fistula of cryptoglandular origin (Table 1). Moreover, we excluded 1 patient who had presented with an actinomycotic abscess but no obvious cryptoglandular origin to its anal fistula. We, therefore, described 13 cases from over 7,000 patients over 30 years. This condition, thus, represents less than $0.2 \%$ of all fistulae in ano.

The 7 new cases include 6 males and 1 female, with a median

Table 1. Characteristics of the patients $(n=7)$ and fistulae in the present study

\begin{tabular}{lc}
\hline Characteristic & Value \\
\hline Patient & \\
\hline Age (yr) & $49(19-72)$ \\
Sex, male : female & $6(86): 1(14)$ \\
Body mass index $\left(\mathrm{kg} / \mathrm{m}^{2}\right)$ & $28.3(25-36.7)$ \\
Active smokers & $3(43)$ \\
\hline Inflammatory bowel disease & $1(14)$ or $2(29)$ \\
NSAIDs & $3(43)$ \\
Average number of previous surgeries & $2.6(1-5)$ \\
Fistulae & \\
Complexity, single : complex & $0(0): 7(100)$ \\
\hline Type*, TS : SS & $6(86): 1(14)$ \\
Horseshoe extension & $2(29)$ \\
High intersphincteric extension & $5(71)$ \\
Suprelevatori extension & $2(29)$ \\
\hline
\end{tabular}

Values are presented as mean (range) or number (\%).

NSAID, nonsteroidal anti-inflammatory drug; TS, transsphincteric; SS, suprasphincteric.

*According to Park's classification system [4]. age at diagnosis of 49 years (range, 19-72 years). The median body mass index (BMI) was $28.3 \mathrm{~kg} / \mathrm{m}^{2}$, with a range of $25-36.7$ $\mathrm{kg} / \mathrm{m}^{2}$. These data are comparable to the data in our previous study (Table 2). One patient received an immunosuppressive drug (azathioprine) and then a tumor necrosis factor-alpha inhibitor (infliximab) for colonic Crohn disease that had been diagnosed 6 months earlier. A second patient presented with ileal ulcerations, but a diagnosis of inflammatory bowel disease was not established during the 15-month follow-up.

Similar to our previous data, the 1 woman in the new series had never used and intrauterine device. All patients were human immunodeficiency virus (HIV)-negative. Three patients were taking nonsteroidal anti-inflammatory drugs ( 2 oral and 1 suppository), one had type 2 diabetes, and 3 were active smokers. All patients complained of an acute and painful ischioanal abscess and 5 had received previous surgical care (1 to 3 procedures) at other centers. The mean time interval from symptom onset to diagnosis was 5.6 years. This time interval ranged from 2 days to 1.5 years for 6 of the 7 patients but was 30 years for 1 patient.

One patient exhibited macroscopic small yellow granules ("sulfur granules"). The fistula exuded serosanguineous pus, known as watery pus of Fry et al. [3] in 1 case. Multiple indurated purplish areas where found on the gluteal zone in 1 patient, witnessing what we call "subcutaneous gluteal septic metastasis." Morphological explorations were performed for only 4 patients. The cryptoglandular origin of the suppuration was confirmed by endoanal ultrasound in 1 patient and by magnetic resonance imaging (MRI) in a second. Both endoanal ultrasound and MRI were performed in the 2 other patients, 1 exploration, but not the other, confirming the cryptoglandular origin of the suppuration. A nonspecific fistula-in-ano was visualized in all 4 patients.

During surgical exploration, all fistulous tracts were found to have a complex and generally posterior $(n=5)$ cryptoglandular origin. The Park's abscess classifications [4] were high-transsphincteric $(\mathrm{n}=4)$, supra-sphincteric $(\mathrm{n}=1)$, and horseshoe $(\mathrm{n}=$ 2). Surgical exploration revealed 5 high intersphincteric extensions and 2 supralevator extensions (Table 1). Associated anal stenosis was observed in a patient who did not have inflammatory bowel disease at the first operation. One patient exhibited sulfur granules.

A sample of pus was taken in 5 out of the 7 patients, with special request for actinomycosis analysis for 2 of the 5 samples, but all cultures were negative. Of note is that in our previous study, 2 cultures out of 6 were positive for actinomycosis ( 1 for $A$. israelii and 1 for Actinomyces meyeri) and above all, in those 2 cases, the histological examinations were negative. Systematical histological examinations of the excised tissues were positive (Fig. 1) for Actinomyces in all 7 patients (first procedure specimen in 4 patients; second procedure specimen in 3). Search for evidence of Actinomycosis was requested when the specimen had an atypical aspect $(n=2)$ or because of suspected Crohn disease $(n=2)$.

All patients underwent surgery at our center (median number 


\section{$\begin{aligned} \text { Annals of } & \text { Cases and a Revier } \\ \text { Coloproctology } & \text { Axel Egal, et al }\end{aligned}$}

Table 2. Characteristics of the patients $(n=13)$, fistulae and antibiotherapies in both studies

\begin{tabular}{|c|c|c|c|}
\hline Characteristic & Bauer et al. [1] & Present study & Combination \\
\hline \multicolumn{4}{|l|}{ Patient } \\
\hline Number of patients & 6 & 7 & 13 \\
\hline Age (yr) & $53(32-63)$ & $49(19-72)$ & $51(19-72)$ \\
\hline Sex, male : female & $5(83): 1(17)$ & $6(86): 1(14)$ & $11(85): 2(15)$ \\
\hline \multicolumn{4}{|l|}{ Fistulae } \\
\hline Complexity, single : complex & $1(17): 5(83)$ & $0(0): 7(100)$ & 1 (8) : 12 (92) \\
\hline Type $^{\star}$, TS : SS & $5(83): 1(17)$ & $6(86): 1(14)$ & $11(85): 2(15)$ \\
\hline Horseshoe extension & $2(33)$ & $2(29)$ & $4(31)$ \\
\hline \multicolumn{4}{|l|}{ Oral antibiotic therapy } \\
\hline Mean duration (wk) & $21.3(4-78)$ & $49.1(16-180)$ & $36.3(4-180)$ \\
\hline \multicolumn{4}{|l|}{ Initial antibiotherapy } \\
\hline Aminopenicillin & 3 (50) (3 to 4 g/day) & $0(0)$ & $3(23)$ \\
\hline $\mathrm{CA}$ & $0(0)$ & 5 (71) (3 to 4 g/day) & $5(39)$ \\
\hline Amoxicillin + ACA & 1 (17) (1 and 2 g/day) & 2 & (29) (3 g/day each) \\
\hline Tetracyclines & 2 (33) (2 g/day) & $0(0)$ & $2(15)$ \\
\hline
\end{tabular}

Values are presented as mean (range) or number (\%).

TS, transsphincteric; SS, suprasphincteric; CA, clavulanic acid; ACA, amoxicillin-clavulanic acid.

*According to Park's classification system [4].

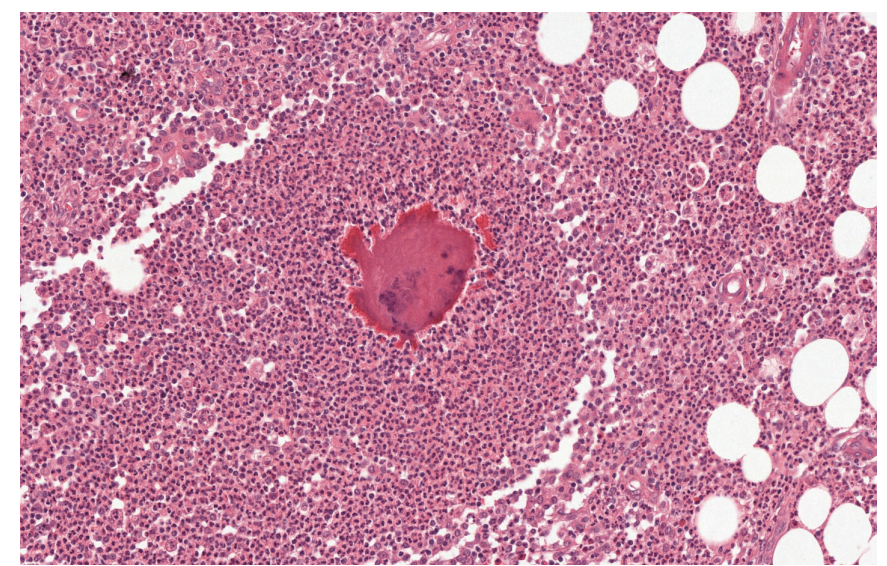

Fig. 1. Actinomycosis in an anal fistula. The characteristics of an actinomycotic granule can be seen, enveloped by a purulent exudate $(\mathrm{H} \& \mathrm{E}, \times 200)$.

of operations, 2.6; range, 1 to 5). The first operating time involved practicing drainage with a loose seton, except in 1 patient who had a 1-time excision of the fistulous tract. Four patients had at least 1 supplementary drainage in order to simplify the fistulous tract. The last operating time mainly involved the establishment of a rubber seton that was then gradually tightened $(n=4)$. Injection of biological glue was performed in 1 patient. The last patient with a loose seton was lost to follow-up.

All patients received prolonged aminopenicillin oral antibiotic therapy (amoxicillin with or without clavulanic acid, from 3 to $6 \mathrm{~g}$ per day) combined with surgery (Table 2). In 2 cases, this treatment was switched to a tetracycline regimen, in the first case because of elevated plasma levels of free bilirubin and in the second one because of unexplained fever. Median treatment duration was 12 months (range, 4-45 months). Excepting the 1 patient who underwent 5 surgical procedures and consequently had a 45-month antibiotic treatment, the median treatment duration was 7 months. Antibiotics were discontinued when the surgical wound had completely healed $(n=4)$ or earlier $(n=2)$. One patient was lost to follow up. We observed no other localization and no relapse or recurrence after the combined treatment. Outcome was favorable with normal continence during the follow-up (average follow-up was 3 years counting from the first surgery, with a range from 6 months to 9 years).

\section{DISCUSSION}

With 7 new cases, we describe the largest case series involving an actinomycotic fistula-in-ano published in more than 3 decades. Primary anoperineal actinomycosis remains a rarity, with to our knowledge, only 21 reported cases involving an actinomycotic fistula-in-ano of obvious cryptoglandular origin, including our 13 cases $[1,2]$. The cases presented here are quite similar to those we previously reported (Table 2 ). We have not observed any change in the clinical manifestations, the morphological or histological features, and the need to adapt the antibiotic or surgical strategy. However, the total duration of antibiotic therapy was longer in our current study and the use of clavulanic acid more widespread; 
we have no explanation for this change (Table 2). The typical patient remains an adult male (only 2 females with this condition, including the 1 reported here, have been reported in the literature). In this series, the median age was 55 years (range, 27-82 years). We found that all of our patients were either overweight or obese. This association has not been described before, although a link with diabetes is known to exist.

The disease occurs in immunocompetent, as well as immunosuppressed, individuals $[5,6]$, regardless of the cause of the immunodeficiency ( 2 cases of HIV-infected patients in the literature) [5]. However, the disease seems to be much more invasive in immunodepressed individuals [7]. Although actinomycosis was discovered more than 1 hundred years ago $[8,9]$, it remains poorly understood, probably because of its rarity and the problems encountered in establishing the diagnosis [10].

These bacteria are part of the human commensal flora (endogenous infection) and are mainly found in the oropharynx, the digestive tract and the urogenital area. The shift to an overt disease requires complex mechanisms that are still obscure. One hypothesis is that the bacteria, which are localized in the mucosa, cannot invade deeper tissues unless facilitating trauma occurs, possibly even years before the infection in certain cases $[5,11]$. We were unable to identify any traumatic event involving our patients whose actinomycosis was diagnosed at the time of their first surgery. For patients who had had prior surgery at other centers, we do not know if the actinomycosis was present at first and not recognized or appeared later. The presence of a copathogen that would inhibit host defense mechanisms or limit available oxygen appears to be necessary for actinomycosis to develop [12, 13]. Human-to-human transmission has never been described.

Surprisingly in this series, all patients complained of an acute painful abscess, and according to the classical description, a painless abscess is the leading feature suggestive of anal suppuration due to cryptoglandular actinomycotic infection. In the previous literature, a painful abscess had been reported in only 2 patients [1]. Prior surgery is another common feature and was observed in 5 of the 7 cases in this series and in 6 of the 14 previously reported cases $[3,14]$. The third classical clinical feature is the presence of macroscopic yellow, sulfur granules, in the pus, which was observed in 1 case in this series and in 5 cases of 14 cases in the literature $[3,14]$. Serosanguineous pus, known as watery pus of Fry et al. [3], is another clue. We had only one patient with watery pus in this series and three others in the previous series $[1,3]$. Watery pus is not necessary for diagnosis $[1,2]$.

Differential diagnoses are anal fistula with common bacteria, tuberculosis, Crohn disease, and exceptionally cancer. The diagnosis of actinomycosis ideally requires a positive culture to ensure precise identification and antibiotic susceptibility testing, but isolation and identification of Actinomyces is difficult and, thus, is achieved in only a minority of the cases [15]. Despite specific information given to the laboratory, bacteriological study failed to find any evidence of actinomycosis, and no specific species could be identified. Only 5 positive cultures have been reported in the literature $[1,3]$. More than 40 Actinomyces species have been described in the literature, many of which do not cause human infection $[16,17]$. Most human infections are due to A. israelii $[5,6$, 18]. Recently, several studies have shown that invasive Actinomycoses are frequently due to A. meyeri [17]. In routine practice, when the clinical presentation is typical and bacteriological proof is lacking, the surgical specimen's histopathological characteristics (typical bacilli surrounded by inflammatory cells, mostly neutrophils) should be accepted as a key element for diagnosis. That clinicians inform the laboratory specialists that Actinomyces infection is suspected is important so that adequate procedures can be adopted: complementary stains (Grocott, HES, PAS...), appropriate culture media, prolonged culture (5 to 20 days), and sometimes more sophisticated identification techniques, such as $16 \mathrm{~S}$ rRNA PCR [19, 20], MALDI TOF mass spectrometry [21], or classical tests, such as API 20 A or API RAPID ID ANA (BioMérieux, Marcy-l'Étoile, France) [12].

Prolonged antibiotic therapy, together with surgery, is the mainstay treatment. Antibiotic therapy is still based on old and noncomparative data and, thus, is not consensual. A high-dose penicillin regimen is usually given for an extended period. The median duration was 12 months in our series. This is longer than the duration reported in the literature for this anatomical location (9 months) [1]. No antimicrobial resistance seems to have emerged since our previous study in 2006 [1]. Other antibiotics can also be used, particularly if there is a risk of allergic reactions $[5,6]$. Some antibiotics are, however, considered to be ineffective, including azoles, quinolones, aminoglycosides, and first generation cephalosporins [22]. The appropriate duration for antibiotic therapy is controversial, despite the fact that treatment failure is described in the literature for regimens with insufficient duration and insufficient dose $[23,24]$. Some authors have recently proposed to shorten treatment duration, especially if the infection is limited and a surgical treatment (fistulotomy 1 or 2 times) has been performed [25] and has completely removed the lesion. In the absence of other relevant criteria, stopping the antibiotics when the wounds are totally healed seems reasonable [1]. For a classical fistulotomy, 2 -staged surgical treatment is the rule. New sphincter-sparing techniques can also be proposed, e.g., biological glue as used in 1 case in this series after prolonged drainage and antibiotics.

Certain details of 2 specific cases illustrate the importance of combining prolonged antibiotic therapy with surgery to obtain complete healing of cryptoglandular abscesses and fistulae-in-ano due to Actinomyces species. In the first case [1], Actinomyces eradication, which was obtained with oral ampicillin, was unable to prevent relapse of a high and complex transsphincteric fistula because first-line surgical treatment had not undertaken to remove the cryptoglandular origin of the suppuration. In the second case, 1 of 2 reported by Fry et al. [3], exclusive appropriate surgical management achieved healing, but did not prevent a recurrent Actinomyces infection 2 months later. That infection was resolved 
successfully with an appropriate antibiotic given alone, and no further recurrence was observed during the 7-year follow-up.

In conclusion, physicians should be aware of the possibility of actinomycosis as a cause of anal abscesses of cryptoglandular origin. Alerting signs include the presence of sulfur granules in the pus, a patient who has undergone multiple surgeries, or any atypical aspect of the suppuration; however, these signs are not always present. A pus sample should be taken for culture, with specific information for the laboratory to ensure that the necessary conditions for Actinomyces isolation are brought together. Despite this, microbiological examination was not helpful in this series. In all cases, tissue histopathology is essential to make the diagnosis. Common practice is to send bacterial swabs from the perianal abscess, but always the tissue, and the findings of this series are a strong reminder that sending both specimens to the laboratory at every surgery is important. Favorable outcomes can be expected for actinomycotic anal suppuration if appropriate surgical procedures are combined with adequate oral antibiotic therapy. Antibiotic treatment should be continued until the surgical wound has completely healed.

\section{CONFLICT OF INTEREST}

No potential conflict of interest relevant to this article was reported.

\section{REFERENCES}

1. Bauer P, Sultan S, Atienza P. Perianal actinomycosis: diagnostic and management considerations: a review of six cases. Gastroenterol Clin Biol 2006;30:29-32.

2. Coremans G, Margaritis V, Van Poppel HP, Christiaens MR, Gruwez J, Geboes K, et al. Actinomycosis, a rare and unsuspected cause of anal fistulous abscess: report of three cases and review of the literature. Dis Colon Rectum 2005;48:575-81.

3. Fry RD, Birnbaum EH, Lacey DL. Actinomyces as a cause of recurrent perianal fistula in the immunocompromised patient. Surgery 1992;111:591-4.

4. Parks AG, Gordon PH, Hardcastle JD. A classification of fistulain-ano. Br J Surg 1976;63:1-12.

5. Wong VK, Turmezei TD, Weston VC. Actinomycosis. BMJ 2011; 343:d6099.

6. Russo TA. Agents of actinomycosis. In: Bennett JE, Dolin R, Blaser MJ, editors. Principles and practice of infectious diseases. 8th ed. Philadelphia (PA): Elsevier Saunders; 2015. p. 2864-72.

7. Pierre I, Zarrouk V, Noussair L, Molina JM, Fantin B. Invasive actinomycosis: surrogate marker of a poor prognosis in immunocompromised patients. Int J Infect Dis 2014;29:74-9.

8. Israel J. Neue beobachtungen auf dem gebiete der mykosen des menschen. Arch Pathol Anat 1878;74:15-53.

9. Kruse W. Systematik der streptothricheen und bakterien. In: Flugge C, editor. Die mikroorganismen. 3rd ed. Vol 2. Leipzig: Vogel; 1896. p. 48-96.

10. Acevedo F, Baudrand R, Letelier LM, Gaete P. Actinomycosis: a great pretender. Case reports of unusual presentations and a review of the literature. Int J Infect Dis 2008;12:358-62.

11. Smego RA Jr, Foglia G. Actinomycosis. Clin Infect Dis 1998;26: 1255-61.

12. Jordan HV, Kelly DM, Heeley JD. Enhancement of experimental actinomycosis in mice by Eikenella corrodens. Infect Immun 1984;46:367-71.

13. Glahn M. Cervico-facial actinomycosis; etiology and diagnosis. Acta Chir Scand 1954;108:183-92.

14. Alvarado-Cerna R, Bracho-Riquelme R. Perianal actinomycosis: a complication of a fistula-in-ano. Report of a case. Dis Colon Rectum 1994;37:378-80.

15. Bennhoff DF. Actinomycosis: diagnostic and therapeutic considerations and a review of 32 cases. Laryngoscope 1984;94:1198217.

16. Valour F, Sénéchal A, Dupieux C, Karsenty J, Lustig S, Breton P, et al. Actinomycosis: etiology, clinical features, diagnosis, treatment, and management. Infect Drug Resist 2014;7:183-97.

17. Eng RH, Corrado ML, Cleri D, Cherubin C, Goldstein EJ. Infections caused by Actinomyces viscosus. Am J Clin Pathol 1981;75: 113-6.

18. Fazili T, Blair D, Riddell S, Kiska D, Nagra S. Actinomyces meyeri infection: case report and review of the literature. J Infect 2012;65: 357-61.

19. Felz MW, Smith MR. Disseminated actinomycosis: multisystem mimicry in primary care. South Med J 2003;96:294-9.

20. Clarridge JE 3rd, Zhang Q. Genotypic diversity of clinical Actinomyces species: phenotype, source, and disease correlation among genospecies. J Clin Microbiol 2002;40:3442-8.

21. Ng LS, Sim JH, Eng LC, Menon S, Tan TY. Comparison of phenotypic methods and matrix-assisted laser desorption ionisation time-of-flight mass spectrometry for the identification of aerotolerant Actinomyces spp. isolated from soft-tissue infections. Eur J Clin Microbiol Infect Dis 2012;31:1749-52.

22. Marchand-Austin A, Rawte P, Toye B, Jamieson FB, Farrell DJ, Patel SN. Antimicrobial susceptibility of clinical isolates of anaerobic bacteria in Ontario, 2010-2011. Anaerobe 2014;28:120-5.

23. Harvey JC, Cantrell JR, Fisher AM. Actinomycosis: its recognition and treatment. Ann Intern Med 1957;46:868-85.

24. Shulman H. Actinomycosis, pleural and abdominal, treated with penicillin: case report. Med Bull Vet Adm 1944;21:230-1.

25. Simpson JA, Banerjea A, Scholefield JH. Management of anal fistula. BMJ 2012;345:e6705. 